\title{
A 'small-world-like' model for comparing interventions aimed at preventing and controlling influenza pandemics Fabrice Carrat*1,2, Julie Luong ${ }^{1,3}$, Hervé Lao ${ }^{1}$, Anne-Violaine Sallé1, Christian Lajaunie ${ }^{3}$ and Hans Wackernagel ${ }^{3}$
}

\begin{abstract}
Address: ${ }^{1}$ Université Pierre et Marie Curie-Paris6, INSERM, UMR-S 707, Paris F-75012, France, ${ }^{2}$ Assistance Publique Hôpitaux de Paris, Hôpital Saint-Antoine, Paris F-75012, France and ${ }^{3}$ Centre de Géostatistique de l'Ecole des Mines de Paris, Fontainebleau F-77300, France

Email: Fabrice Carrat* - carrat@u707.jussieu.fr; Julie Luong - 02luong@ensmp.fr; Hervé Lao - herve.lao@u707.jussieu.fr; AnneViolaine Sallé - salle@u707.jussieu.fr; Christian Lajaunie - Christian.Lajaunie@ensmp.fr; Hans Wackernagel - Hans.Wackernagel@ensmp.fr

* Corresponding author
\end{abstract}

Published: 23 October 2006

BMC Medicine 2006, 4:26 doi:10.1186/174I-70/5-4-26
Received: 22 February 2006

Accepted: 23 October 2006

This article is available from: http://www.biomedcentral.com/174I-70I5/4/26

(C) 2006 Carrat et al; licensee BioMed Central Ltd.

This is an Open Access article distributed under the terms of the Creative Commons Attribution License (http://creativecommons.org/licenses/by/2.0), which permits unrestricted use, distribution, and reproduction in any medium, provided the original work is properly cited.

\begin{abstract}
Background: With an influenza pandemic seemingly imminent, we constructed a model simulating the spread of influenza within the community, in order to test the impact of various interventions.

Methods: The model includes an individual level, in which the risk of influenza virus infection and the dynamics of viral shedding are simulated according to age, treatment, and vaccination status; and a community level, in which meetings between individuals are simulated on randomly generated graphs. We used data on real pandemics to calibrate some parameters of the model. The reference scenario assumes no vaccination, no use of antiviral drugs, and no preexisting herd immunity. We explored the impact of interventions such as vaccination, treatment/prophylaxis with neuraminidase inhibitors, quarantine, and closure of schools or workplaces.

Results: In the reference scenario, $57 \%$ of realizations lead to an explosive outbreak, lasting a mean of 82 days (standard deviation (SD) 12 days) and affecting $46.8 \%$ of the population on average. Interventions aimed at reducing the number of meetings, combined with measures reducing individual transmissibility, would be partly effective: coverage of $70 \%$ of affected households, with treatment of the index patient, prophylaxis of household contacts, and confinement to home of all household members, would reduce the probability of an outbreak by $52 \%$, and the remaining outbreaks would be limited to $17 \%$ of the population (range $0.8 \%-25 \%$ ). Reactive vaccination of $70 \%$ of the susceptible population would significantly reduce the frequency, size, and mean duration of outbreaks, but the benefit would depend markedly on the interval between identification of the first case and the beginning of mass vaccination. The epidemic would affect $4 \%$ of the population if vaccination started immediately, $17 \%$ if there was a 14 -day delay, and $36 \%$ if there was a 28 -day delay. Closing schools when the number of infections in the community exceeded 50 would be very effective, limiting the size of outbreaks to $10 \%$ of the population (range $0.9 \%-22 \%$ ).
\end{abstract}

Conclusion: This flexible tool can help to determine the interventions most likely to contain an influenza pandemic. These results support the stockpiling of antiviral drugs and accelerated vaccine development. 


\section{Background}

There are increasing concerns that an $\mathrm{A} / \mathrm{H} 5 \mathrm{~N} 1$ influenza pandemic is imminent. Based on data from recent pandemics, 50 countries have developed pandemic preparedness plans and most industrialized countries are stockpiling antiviral drugs [1]. An international workforce has been created to develop an H5N1 vaccine [2], and immunogenicity trials are promising $[3,4]$.

Public health decision-making will be based largely on experience with past pandemics, but models are needed to plan and evaluate interventions based on vaccination, antiviral prophylaxis/therapy, quarantine, and closure of public places. As the transmissibility and pathogenicity of emerging influenza viruses cannot be predicted, and neither can their pandemic potential, such models should be flexible enough to be adapted to a wide range of situations. They must deal with various types of populations and test different kinds of interventions, used together or in isolation.

Recent papers focus on the containment of an outbreak in a rural area of Southeast Asia, where a pandemic virus seems most likely to emerge $[5,6]$, or on strategies for mitigating the severity of a pandemic in the United States or Great Britain, where a virus is likely to spread secondarily $[7,8]$. The authors used different methodologies, but the results of both studies showed that a nascent pandemic could be contained by using a combination of antiviral drugs and confinement measures. Another paper suggested that, in the United States, vaccination (particularly of children) could be very effective [9].

We have developed a model for simulating the spread of influenza virus infection in the community during a pandemic. The model includes not only individual parameters, which take into account the risk of infection and the dynamics of viral shedding according to age, treatment, and vaccination status, but also community parameters, in which meetings between individuals are simulated by the use of a complex random graph.

\section{Methods \\ Individual-centered model of influenza infection, illness, and health-care use}

A computer model was first developed to describe influenza infection and its consequences for a given individual. We used the classical four-stage model of infection, as follows: Susceptible ( $\mathrm{S}$ - may be infected), Exposed (E - is infected but cannot transmit the disease), Infectious ( $\mathrm{I}$ - is infected and can transmit the disease), and Recovered ( $\mathrm{R}$ - can no longer transmit the disease and is immune to new infections).

The three basic parameters used to describe transitions between the different stages were the person-to-person transmission rate, which is assumed to vary with the age of susceptible and infectious individuals and with the time since infection; the length of the latent period (time between infection and onset of infectivity); and the length of the infectious period.

In order to obtain a biologically realistic description of the person-to-person transmission process, we assumed that infectivity varies with time since infection and is proportional to the degree of viral shedding by infected individuals (Table 1). Based on data from experimental studies in which viral shedding was measured in volunteers challenged with wild-type influenza viruses $[10,11]$, we modeled the kinetics of infectivity by using [l.c. gamma] density functions with a fixed offset of 0.5 days, corresponding to the latent period (Figure 1). The profiles thus obtained were consistent with those of a prospective household-contacts survey conducted in France, with peak infectivity between the second and third days after infection, infectivity lasting a maximum of 10 days, and 1.8-fold-higher daily infectivity of children compared with adults $[12,13]$. Finally, we modulated individual susceptibility by age, again based on the results of the pro-

Table I: Parameters describing the transmissibility and pathogenicity of influenza virus.

\begin{tabular}{|c|c|c|}
\hline Parameter & Baseline values & Sources \\
\hline Infectivity profiles & & $\begin{array}{l}\text { Adapted from [13], and consistent (to a scale factor) with } \\
{[10,15-2 \mid]}\end{array}$ \\
\hline Latent period & 0.5 days & \\
\hline Peak & $2.5-3$ days & \\
\hline Duration & $<10$ days & \\
\hline Relative susceptibility & & {$[5,13]$} \\
\hline Children (0-18 years) & 1.15 & \\
\hline Adults ( $19-65$ years) & 1 & \\
\hline Elderly (>65 years) & I & \\
\hline Proportion of asymptomatic individuals (children, adults, elderly people) & $30 \%$ & [48]; also used in [6] \\
\hline Relative infectivity of asymptomatic individuals & $50 \%$ & Assumption also used in [6] \\
\hline
\end{tabular}




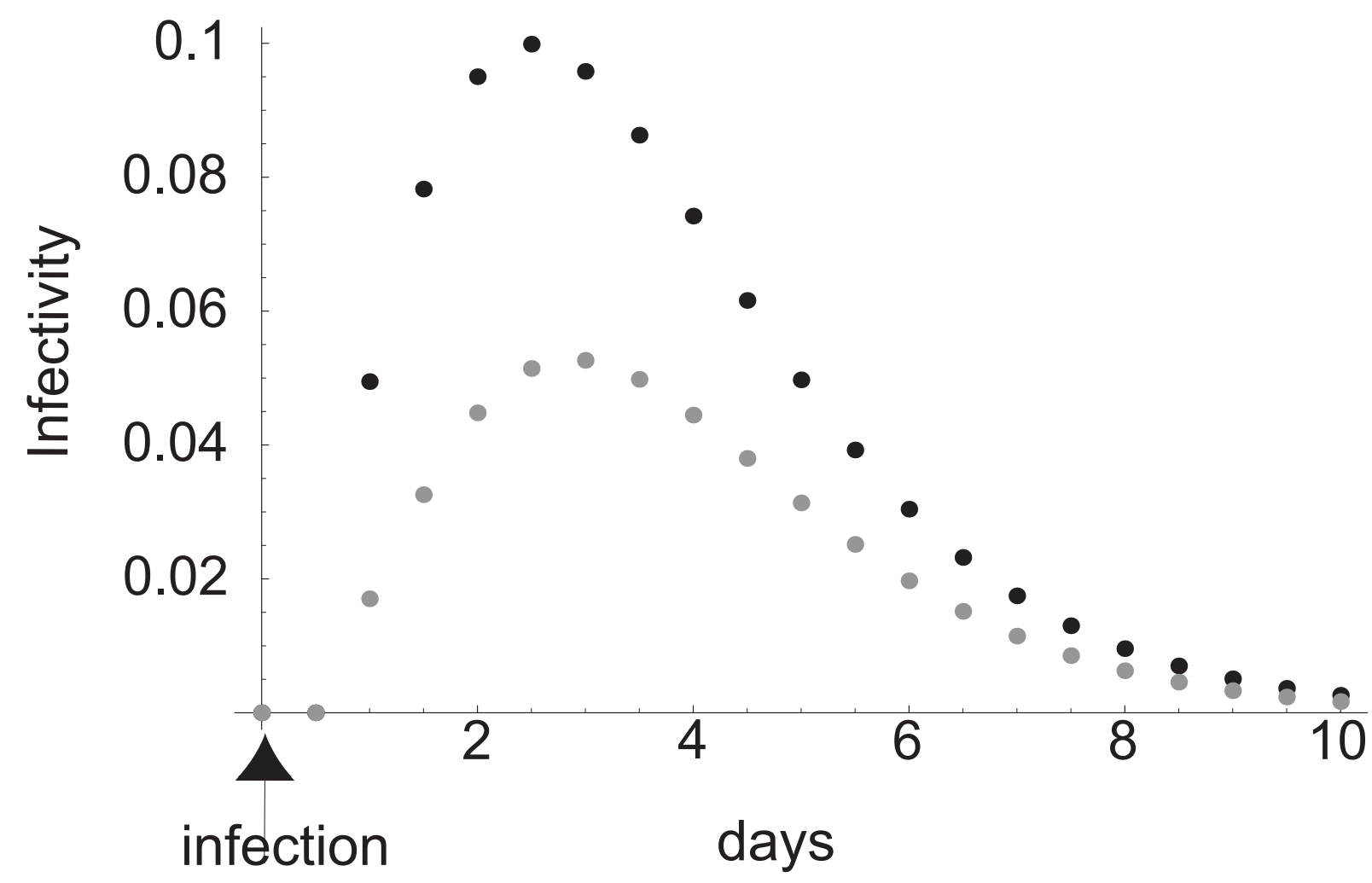

Figure I

Infectivity profiles of individuals according to time since influenza infection. A latent period of 0.5 days was postulated. Black dots represent infectivity in children and grey dots, infectivity in adults or elderly subjects.

spective survey, in which we showed that susceptibility was higher in children than in adults [14]. The infectivity profiles were then scaled by a factor that was identical for children and adults in order to obtain attack rates consistent with those reported during pandemics in children and adults or the elderly (see below). The resulting probability of transmission during a hypothetical meeting lasting throughout the infective period between a susceptible child and a single infected child was $64 \%$; the corresponding probability of transmission between a susceptible adult and a child was 58\%; the corresponding values for permanent meetings between a single infected adult and a susceptible child and adult were $42 \%$ and $37 \%$, respectively.

As influenza virus infection is not always symptomatic, we postulated that $30 \%$ of infected individuals would not be sufficiently ill to be identifiable [6], and that these subjects would be half as infective as other subjects. For symptomatic individuals, we postulated that the duration and intensity of symptoms would be proportional to infectiv- ity, based on the observation that the onset of symptoms after experimental infection coincides with a sharp increase in viral shedding [10,15-21], i.e. the incubation period is equal to the latent period.

For case and contact tracing, and for access to interventions (treatment, prophylaxis, etc.), patients must be seen by a physician. We postulated that most symptomatic subjects would seek medical advice (90\%), and that $40 \%$ of those who consulted would do so within the first day after onset, 30\% the second day, and 30\% after the second day. These rates were chosen to be higher than those observed during a seasonal influenza epidemic [12], as public awareness would be higher in a pandemic situation and as antiviral treatment would be available only from a physician. Finally, we postulated that $80 \%$ of individuals who consulted a physician would remain confined to their home for one week.

We postulated that $5 \%$ to $13 \%$ of symptomatic subjects (depending on age) would be hospitalized for serious 
Table 2: Parameters describing the community model simulating the spread of influenza.

\begin{tabular}{|c|c|c|c|c|}
\hline Place & Size & Graph & Assignment & Meetings \\
\hline Households & 1 to 6 & Fully connected & & $\mathrm{D}$ \\
\hline \multicolumn{5}{|l|}{ Schools } \\
\hline Elementary & $\begin{array}{l}5 \text { classes; } 20 \text { children and } 2 \\
\text { adults per class }\end{array}$ & $\begin{array}{l}\text { Each class is modeled using a BA graph }(m=2) \text {; } \\
\text { supplementary random links between individuals } \\
\text { belonging to different classes. }\end{array}$ & $\begin{array}{l}\text { Children living in the } \\
\text { district }\end{array}$ & WD \\
\hline Secondary & $\begin{array}{l}13 \text { to } 15 \text { classes; } 30 \text { students } \\
\text { and } 3 \text { teachers per class }\end{array}$ & Children and students are linked to teachers. & One college for 5 districts & WD \\
\hline Workplaces & $\begin{array}{l}6 \text { to } 3000 \text { according to Zipf } \\
\text { distribution [49] }\end{array}$ & BA graph $(m=6)$ & $\begin{array}{l}80 \% \text { from the district; } 20 \% \\
\text { from outside the district }\end{array}$ & WD \\
\hline Nursing homes & $\begin{array}{l}45 \text { elderly people, } 50 \\
\text { employees per nursing home }\end{array}$ & BA graph $(m=6)$ & & WD \\
\hline District & All individuals & BA graph $(m=1)$ & & WE \\
\hline
\end{tabular}

BA Barabasi-Albert; D every day; WD every working day; WE every weekend

complications and that $20 \%$ to $30 \%$ of those hospitalized would die. The case-fatality rates thus ranged from $1 \%$ to $4 \%$, in keeping with data collected during previous pandemics $[22,23]$ The average hospital stay was set at 12 days, based on French national statistics on hospitalization for pneumonia and influenza [24]. We postulated that transmission could not occur between patients or from patients to hospital staff, owing to strict application of preventive measures.

\section{Community model}

The community model was based on a complex random graph realistically describing meetings between individuals. We first generated a set of individuals based on a particular demographic profile (gender, age groups, and household sizes) adapted from French national census data [25], in which each individual is assigned to a household and a place of occupation (for example, a school for a child, or a workplace for a working adult). Households and places of occupation were assigned to districts, and children were preferentially assigned to schools located in the district where they lived; $20 \%$ of working adults were assigned to workplaces located in other districts. In the reference simulation, $23 \%$ of individuals were children, $67 \%$ were adults ( $80 \%$ in employment), and $10 \%$ were elderly.

Two types of bidirectional graphs were generated. First, a fully connected graph was generated for each household, as we assumed that every household member would make daily meetings with all other household members (if any).

For schools, workplaces and other locations (nursing homes, hospital, etc), meetings between individuals were modeled with the Barabasi-Albert (BA) random graph [26]. The BA graph was developed in the late 1990s to describe systems in which the probability that a node will have a given number of connections with other nodes does not depend on the size of the system. This type of graph can correctly describe systems such as links on the worldwide web and citations in scientific journals $[27,28]$. It can also provide a realistic representation of social contacts: the first application of this method was to describe the network of movie actors [28]).

BA graphs are built up from a small initial numbers of nodes (three, for example), in two steps: a growth step, in which a new node with $m$ connections is added; and a preferential attachment step, in which the nodes to which the new node connects are chosen. The probability $\Pi$ that the new node will be connected to node $i$ depends on the connectivity $k_{i}$ of that node, such that $\Pi\left(k_{i}\right)=k_{i} / \sum_{j} k_{j}$.

The probability density $P(k)$ that a node in the network is connected to $k$ other nodes is independent of the size of the system and has a power law distribution, that is $P(k) \sim$ $A k^{-\gamma}$, where [l.c. gamma] is 3 and coefficient $A$ is proportional to the square average connectivity of the network ( $A$ $\sim m^{2}$ ). The average connectivity of a BA graph is $2 m$.

Various BA graphs were generated for the various locations simulated here (Table 2).

Figure 2 describes the resulting connectivity $(k)$ of the simulated population (100 simulations). The connectivity clearly followed a power-law distribution for $k$ values $>10$. The mean connectivity was 11.9 (standard deviation (SD) 0.28 ), with differences according to age: 13.6 (SD 0.06) for children, 12.3 (SD 0.41) for adults, and 4.8 (SD 0.14) for elderly people. We also calculated a weighted connectivity by scaling each connection by a factor representing the part of the week during which individuals met and during which transmission could occur if one individual was infectious and the other susceptible. For example, meetings between household members, assumed to occur 


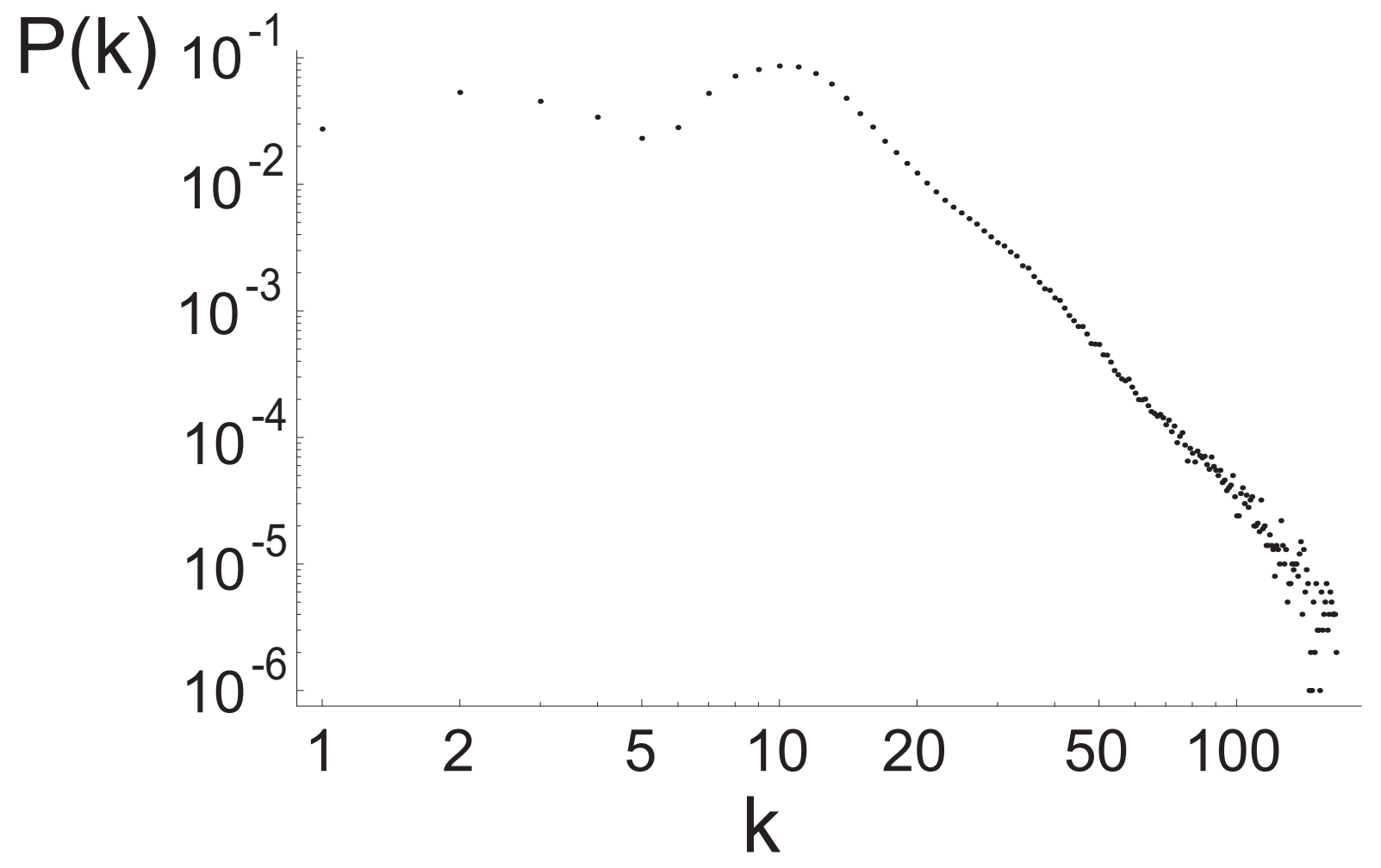

Figure 2

Connectivity distribution of the simulated population.

every morning and every evening of each working day and during the entire weekend, corresponded to 9/14ths of a week. Meetings between employees or school children were equivalent to 5/14ths of a week. The resulting weighted connectivity was 3.87 (SD 0.09), meaning that an individual in our simulated network had an average of nearly 4 permanent meetings with other individuals. We characterized the mixing of the simulated population by computing a mean local clustering coefficient $C$, defined as the mean fraction of existing connections between contacts of each individual. $C$ reflects the existence of cliques, or communities: it is the mean probability that two individuals are connected, given that they share a common network contact. The mean local clustering coefficient of the simulated graphs was 0.20 (SD 0.02). Finally, the mean shortest path (the minimum number of contacts) between two randomly chosen individuals in our simulated population was 3.6 (SD 0.15). Thus, our networks exhibited substantial clustering and small-world properties consistent with current knowledge of human social networks [29].

\section{Simulation process and empirical calibration}

Each simulation started with the generation of a network of 10,000 individuals and one infected individual. In order to deal with heterogeneities of susceptibility or connectivity between individuals, we proceeded as follows: we first randomly chose one infected individual and then simulated the first generation of secondary infections. Then each individual infected during the first generation was used as the initial infective in a new simulation where the network and the population were reset to their initial values. The selection of an individual from the first generation ensures proper sampling of the initial infected individual in a heterogenous contact network [30].

A discrete time step (half a day) was chosen. At each time point, meetings between infectious and susceptible individuals were derived from the graph, and transmission of influenza virus during each meeting was simulated by comparing a uniform random number with the calculated probability of transmission. The per-meeting probability of transmission was calculated as the product of infectivity 


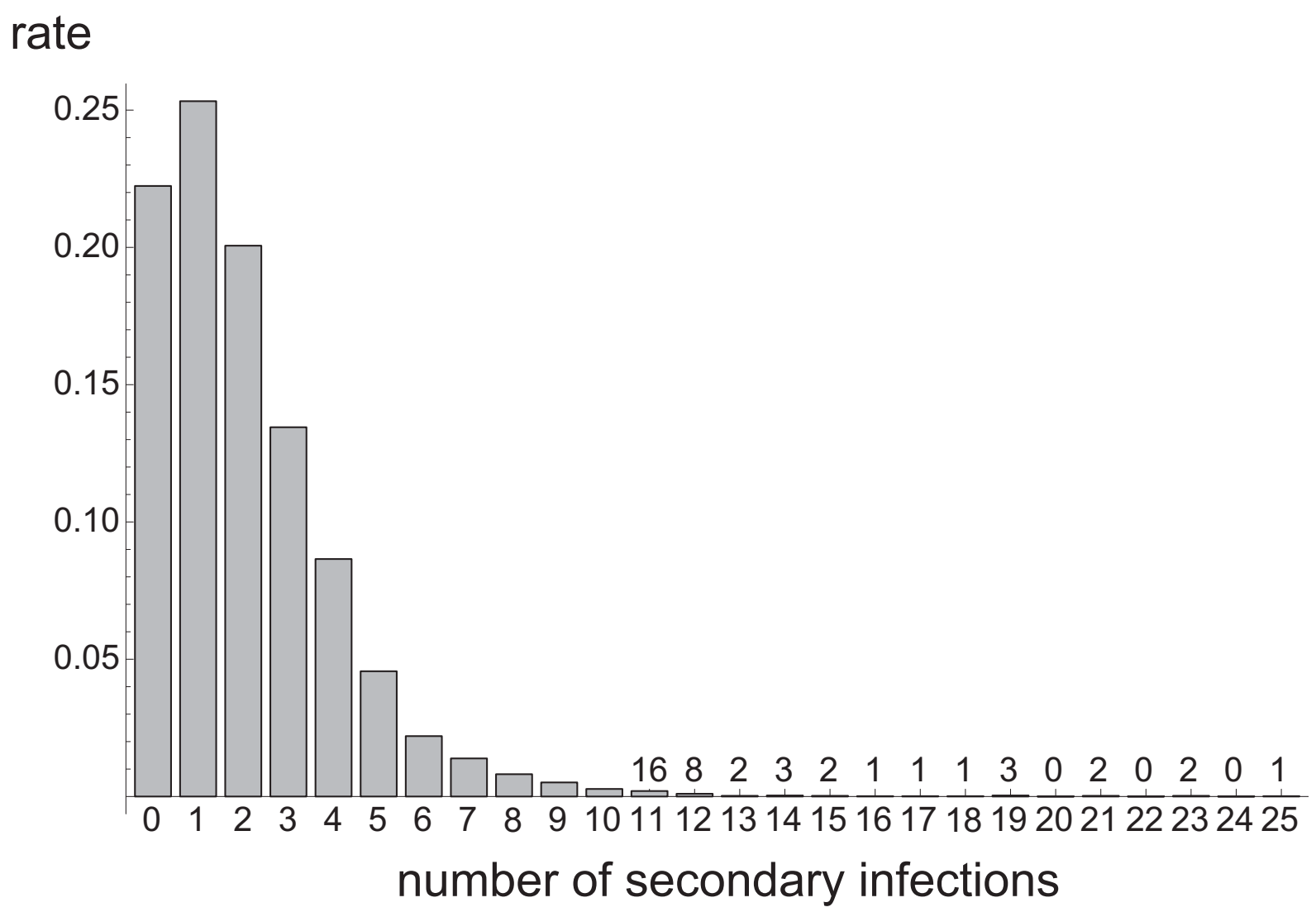

Figure 3

Distribution of the basic reproductive number $\boldsymbol{R}_{\mathbf{0}}$. There were 8000 simulations. Superscripts indicate the numbers of simulations generating a number of secondary infections greater than 10 .

(depending on time since infection) and the relative susceptibility of the contact, and was adjusted for other parameters (vaccination, treatment, etc.). The simulations stopped after the maximal length of the infectious period following the last transmission event.

A critical parameter in the epidemiology of infectious diseases is the basic reproductive number $\left(R_{0}\right) . R_{0}$ is defined as the average number of secondary infections produced by a single infected person in a fully susceptible population. In our model, analytical calculation of $R_{0}$ is not feasible [6]. For this reason, we proceeded by simulation, randomly choosing one infective subject as described above, and then counting the number of secondary infections.

Figure 3 shows the distribution of the numbers of secondary infections averaged over 8000 trials. In $22.2 \%$ of trials, no secondary cases were generated by the introduction of a single infectious individual into the community. The mean $R_{0}$ was 2.07 and the disease generation time, which represents the mean interval between infection of a given person and infection of all the people that this individual infects, was 2.44 (SD 1.48) days.

We then explored the sensitivity of the basic reproductive number to the number of meetings and to the per-meeting probability of transmission. Parameters describing the meetings (mean weighted connectivity between 1 and 7) and per-meeting transmissibility ( 0.1 to 3 times the reference value) were varied on a 10 [multiplication sign] 10 grid with 40 simulations for each combination of parameters. Normal regression analysis with a log link was performed with the mean number of secondary cases as the response variable and weighted connectivity and permeeting transmissibility as predictors. As expected, the mean weighted connectivity and the per-meeting transmissibility correlated independently with the basic reproductive number (Figure 4).

The observed rates of seroconversion and illness due to the pandemic strains that circulated during the $20^{\text {th }}$ cen- 


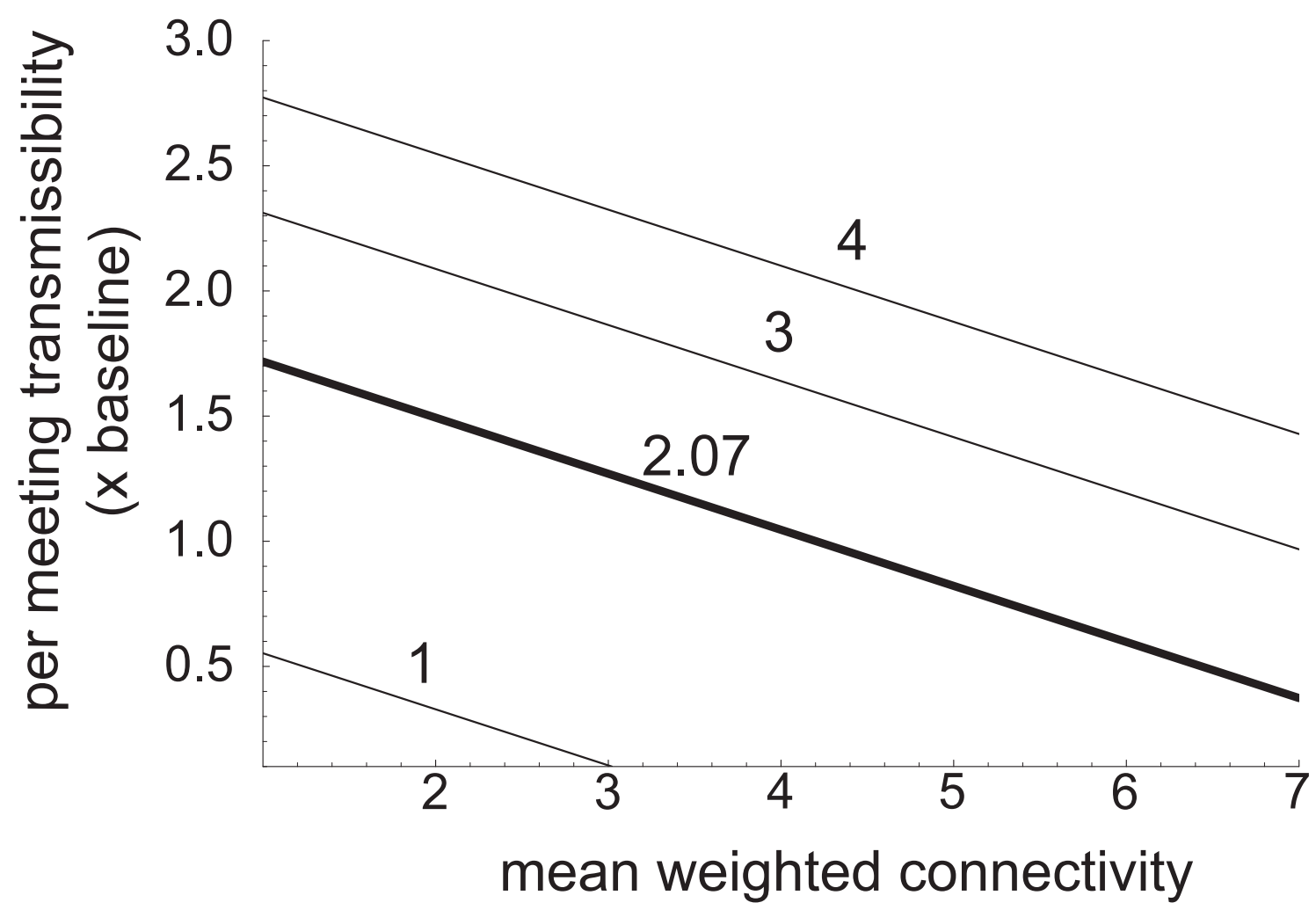

\section{Figure 4}

Sensitivity analysis of the basic reproductive number $\boldsymbol{R}_{\mathbf{0}}$. The figure shows the isopleth of $R_{0}$ as a function of weighted connectivity and multiples of baseline per-meeting probabilities of transmission. The bold line corresponds to $R_{0}=2.07$. Curves were plotted using the following regression equation: $R_{0}=\operatorname{Exp}([$ minus $] 0.485+0.347$ [multiplication sign] multiple of the baseline per-meeting probability of transmission +0.14 weighted connectivity).

tury were used to calibrate the model, and particularly to scale infectivity. During the 1957 pandemic, serological infection rates as high as $75 \%$ were observed among children and 25\% among adults [31]. In 1918, during the first pandemic wave, the attack rate of clinical influenza was maximum in children (40\%) and then fell gradually with age, reaching $9 \%$ in people aged 75 years or more. An average attack rate of 34\% was reported during the 1957 pandemic, with an age distribution similar to that observed during the first pandemic wave of 1918 [23]. The age distribution of attack rates during the 1968 pandemic was noticeably different, with values decreasing less markedly with age, ranging between $41 \%$ and $43 \%$ in children, but remaining above $30 \%$ in all other age groups [23]. Most of these rates were obtained from studies of families with children (which tend to overestimate the true attack rates in the general population), but served as benchmarks for empirical calibration of our model. The shape and length of the pandemic curve were also consist- ent with those reported in cities during the 1918 pandemic [32].

\section{Results}

Reference scenario

Two hundred realizations were simulated for each scenario. Three patterns were observed. No secondary infections were generated in $20 \%$ of simulations (see above). In $23 \%$ of simulations, a limited number of infections occurred and the epidemics always affected fewer than five subjects per 1000 (Figure 5). In the remaining 57\% of simulations, explosive growth occurred and the epidemic affected an average of $46.8 \%$ of subjects (SD 1.7\%). The mean duration of the outbreaks, defined as the time between the first secondary infection and the last infection, was 82 days (SD 12 days). The cumulative incidence rate of influenza infection was much higher in children than in adults, including the elderly. The mean clinical attack rate was 33\% (SD 1\%), $1.7 \%$ (SD $0.16 \%$ ) of the 


\section{Proportion}
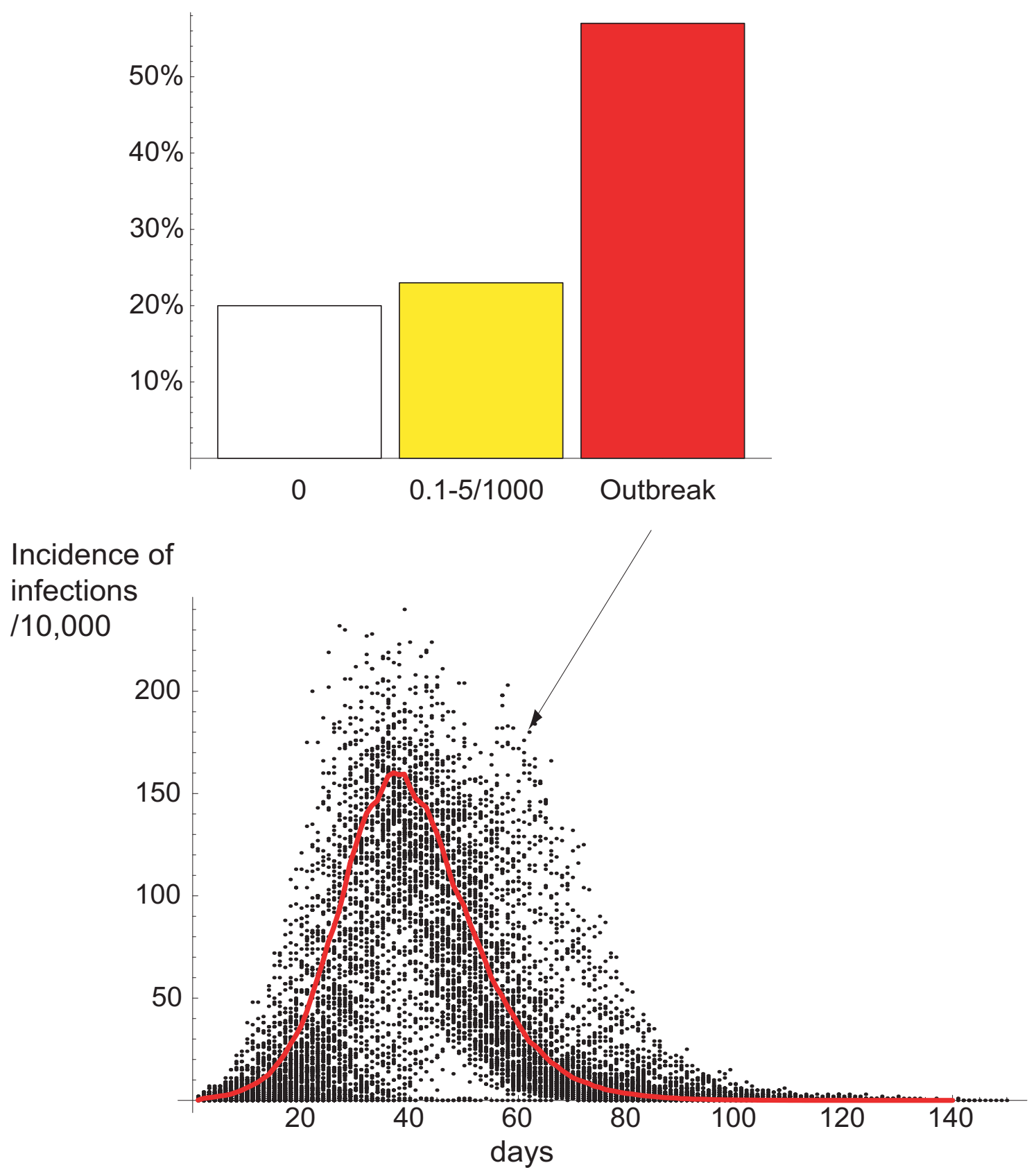

\section{Figure 5}

Simulation of the reference scenario for a flu pandemic (no intervention). The top figure describes the distribution of the numbers of secondary cases following introduction of a single infected individual into the population (200 simulations), and the bottom figure describes the infection curves of simulated outbreaks. The bold line is the average of the simulated outbreaks. 
Table 3: Reference scenario for a flu pandemic after one initial case (no intervention). Estimates are cumulative numbers per 100 inhabitants, unless otherwise specified.

\begin{tabular}{|c|c|c|c|}
\hline \multirow[t]{2}{*}{ Outcomes } & \multicolumn{2}{|c|}{$\begin{array}{c}\text { Outbreak } \\
n=114\end{array}$} & \multirow{2}{*}{$\begin{array}{c}\text { All simulations } \\
n=200 \\
\text { Mean }\end{array}$} \\
\hline & Mean & Minimum-Maximum & \\
\hline \multicolumn{4}{|l|}{ Infections } \\
\hline Total & 46.8 & $42.3-50.5$ & 26.7 \\
\hline Children $(0-18 \text { years })^{a}$ & 76.5 & $71.9-79.7$ & 43.6 \\
\hline Adults (19-65 years) ${ }^{a}$ & 39.9 & $34.8-44.0$ & 22.8 \\
\hline Elderly (>65 years) ${ }^{a}$ & 25.3 & $20.8-30.1$ & 14.4 \\
\hline Physician visits & 31.2 & $28.0-33.7$ & 17.8 \\
\hline Hospital admissions & 1.74 & $1.30-2.30$ & 0.99 \\
\hline Deaths & 0.36 & $0.17-0.55$ & 0.21 \\
\hline Lost workdays ${ }^{b}$ & 137 & $118-150$ & 78 \\
\hline
\end{tabular}

aPer 100 individuals of a given age

bPer 100 working adults

population was hospitalized, and $0.36 \%$ (SD 0.07\%) died from influenza (a value intermediate between the 1918 pandemic $(0.6 \%)$ and the following two pandemics (0.04\%-0.01\%) [33]). The number of workdays lost per working adult was 1.37 (SD 0.07). Other results, averaged over 200 realizations, are shown in Table 3.

\section{Intervention scenarios}

We first simulated the effectiveness of neuraminidase inhibitors in individuals who sought medical advice and were treated for five days. We assumed that treatment reduced infectivity and clinical severity (including the risk of complications and death) by $28 \%$ [5]. We also assumed that treatment would not affect the mean number of workdays lost per patient. Table 4 shows the results for a treatment coverage rate of $90 \%$. An outbreak was simulated in $53 \%$ of cases and the size of the outbreaks and the clinical attack rate were only slightly affected by treatment, owing to a decrease in transmissibility (Table 4). However, the rates of hospitalization and death decreased, mainly as a result of a lower risk of complications in treated individuals. It is noteworthy that drug stockpiles sufficient for $25 \%$ of the population coverage would permit the treatment of $90 \%$ of patients who consult a physician.

Several randomized controlled trials have demonstrated the preventive effectiveness of neuraminidase inhibitors (see [34] for a recent review). We postulated that a 10-day course of prophylaxis with neuraminidase inhibitors would reduce susceptibility to influenza virus infection by $80 \%$ during each meeting $[35,36]$. We tested two scenarios, one with prophylaxis of household contacts but no treatment of the index case, and one combining treatment

Table 4: Treatment with neuraminidase inhibitors of $90 \%$ of individuals consulting a physician for 'flu-like' symptoms. Estimates are cumulative numbers per 100 inhabitants, unless otherwise specified.

\begin{tabular}{|c|c|c|c|}
\hline \multirow[t]{2}{*}{ Outcomes } & \multicolumn{2}{|c|}{ Outbreak; $n=106$} & \multirow{2}{*}{$\begin{array}{c}\text { All simulations; } n=200 \\
\text { Mean }\end{array}$} \\
\hline & Mean & Minimum-Maximum & \\
\hline \multicolumn{4}{|l|}{ Infections } \\
\hline Total & 43.3 & $38.5-48.0$ & 23.0 \\
\hline Children $^{a}$ & 72.5 & $67.9-76.4$ & 38.4 \\
\hline Adults $^{a}$ & 36.5 & $30.6-41.8$ & 19.3 \\
\hline Elderly ${ }^{a}$ & 22.3 & $18.6-26.0$ & 11.8 \\
\hline Physician visits & 28.0 & $24.3-31.2$ & 14.9 \\
\hline Hospital admissions & 0.98 & $0.66-1.18$ & 0.52 \\
\hline Deaths & 0.21 & $0.12-0.32$ & 0.11 \\
\hline Lost workdays ${ }^{b}$ & 125 & $|07-| 4 \mid$ & 66 \\
\hline Treatment units (doses) $\subseteq$ & 243 & $215-269$ & 129 \\
\hline
\end{tabular}

aPer 100 individuals of a given age

bPer 100 working adults

$\subseteq$ Two per day of treatment, five days per patient 
Table 5: Household contact prophylaxis with antiviral drugs, with or without treatment of the index cases. The interventions are applied in $\mathbf{7 0} \%$ of households in which one member consults a physician. Estimates are cumulative numbers per 100 inhabitants, unless otherwise specified.

\begin{tabular}{|c|c|c|c|c|}
\hline \multirow[t]{2}{*}{ Outcomes } & \multicolumn{2}{|c|}{$\begin{array}{c}\text { Prophylaxis } \\
\text { (Outbreak, } n=90 \text { ) }\end{array}$} & \multicolumn{2}{|c|}{$\begin{array}{l}\text { Prophylaxis }+ \text { treatment } \\
\text { (Outbreak, } n=98)\end{array}$} \\
\hline & Mean & Minimum-Maximum & Mean & Minimum-Maximum \\
\hline \multicolumn{5}{|l|}{ Infections } \\
\hline Total & 36.1 & $32.1-40.1$ & 34.2 & $30.8-37.4$ \\
\hline Children ${ }^{a}$ & 61.8 & $57.0-66.2$ & 58.5 & $53.1-64.5$ \\
\hline Adults $^{a}$ & 30.2 & $25.6-35.0$ & 28.8 & $24.2-33.4$ \\
\hline Elderly ${ }^{a}$ & 16.8 & $11.2-21.2$ & 14.9 & $11.3-18.9$ \\
\hline Physician visits & 23.8 & $21.8-27.0$ & 22.2 & $19.6-24.8$ \\
\hline Hospital admissions & 1.18 & $0.70-1.57$ & 0.77 & $0.59-0.98$ \\
\hline Deaths & 0.25 & $0.13-0.43$ & 0.16 & $0.06-0.28$ \\
\hline Lost workdays ${ }^{b}$ & 106 & $94-122$ & 100 & $85-116$ \\
\hline Treatment units (doses) $\subseteq$ & 196 & $179-210$ & 393 & $356-435$ \\
\hline
\end{tabular}

aPer 100 individuals of a given age

bPer 100 working adults

cTwo per day of treatment, five days per patient; one per day of prophylaxis, 10 days per person

of the index case and prophylaxis of household contacts. Table 5 shows the results for $70 \%$ coverage of household contacts and index cases. Combined treatment and prophylaxis would slightly reduce the burden of influenza outbreaks by comparison with contact prophylaxis without treatment of index cases.

We then examined the impact of 10-day confinement to home of all members of households in which a case was identified by a physician, combined with prophylaxis of household contacts and treatment of the index case. This strategy would increase effectiveness by comparison with similar scenarios not involving confinement: coverage of $70 \%$ of affected households would be sufficient to reduce the risk of an outbreak by $52 \%$, restricting it to $17 \%$ of the population (range $0.8 \%-25 \%$ ) (Figure 6). The mean duration of the outbreak would be increased (119 days, SD 22) by comparison with the reference scenario and influenza virus would persist in the population for more than five months in $25 \%$ of simulations.

We also modeled a scenario in which mass vaccination would begin a certain time after identification of the first case $(0,14,28$ days) and in which the target level of vaccine coverage would be achieved within 14 days. We postulated that individual protective immunity would be achieved two weeks after vaccination and that vaccination would reduce susceptibility by $80 \%$ during each meeting (leaky vaccine, meaning that vaccinated individuals would respond by acquiring partial immunity, rather than acquiring either complete immunity or no immunity at all [37]). Mass vaccination could take place in schools, workplaces, nursing homes, hospitals, and physicians' offices.
We assumed that vaccination would lead to the loss of 0.04 workdays per working adult [38].

Reactive mass vaccination would significantly reduce the frequency, size, and mean duration of outbreaks (Figure 6 ), but the benefit would depend closely on how long it took to begin vaccination after identification of the first case (Table 6).

Finally, we simulated an intervention in which schools and workplaces are closed when a threshold number of infections (5/1000 subjects in our example) has been reached in the population and are reopened 10 days after the last observed case of infection. This strategy could be used if vaccines and/or antiviral drugs were in short supply or ineffective. Table 7 shows the results of closure of schools alone or both schools and workplaces. This strategy would be very effective, but would clearly be associated with massive time off work.

\section{Discussion}

Using a realistic description of influenza infection in the individual subject, we show that an influenza pandemic with a burden comparable to that of 20th-century pandemics might be mitigated by combining measures aimed at reducing meeting frequency and virus transmissibility. This conclusion is based on several assumptions $[5,6]$ and would be influenced by average infectivity, variability of infectivity [39], and the frequency and patterns of meetings between individuals [40], as these two dimensions govern the basic reproductive number. We found that an average $R_{0}$ of 2.07 can provide attack rates and pandemic curves consistent with those reported in previous pan- 


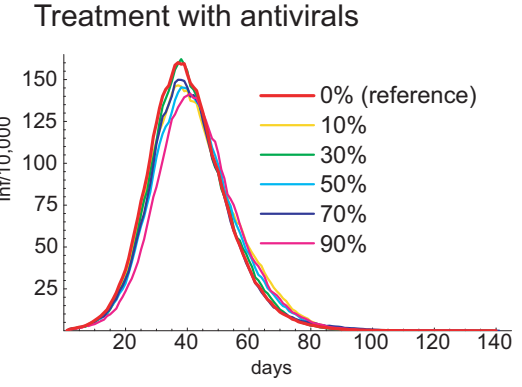

Reactive vaccination ( $70 \%$ coverage)

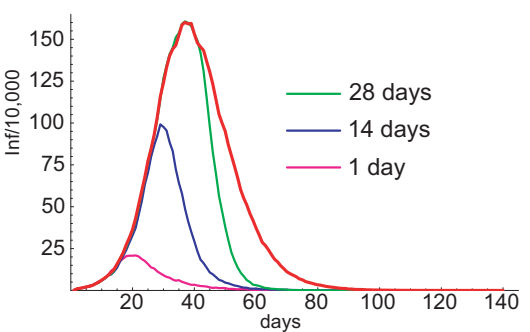

Household contacts prophylaxis

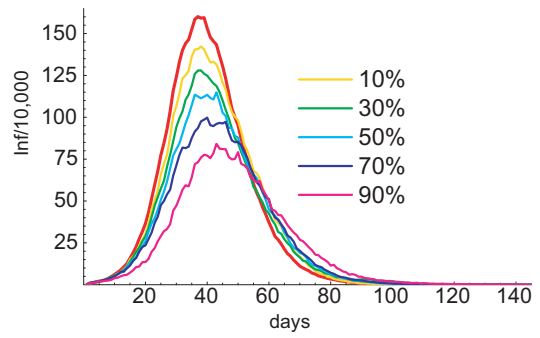

Closure of schools or workplaces (when $>5 / 1000$ infected individuals)

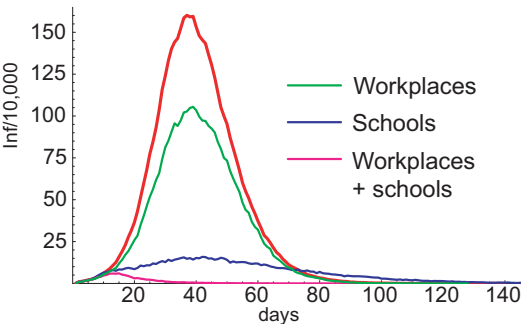

Treatment with antivirals

Household contacts prophylaxis

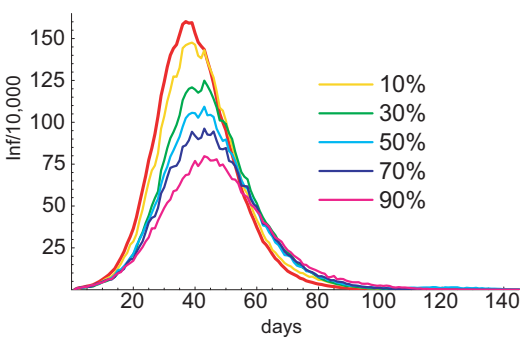

Treatment with antivirals + Household contacts prophylaxis + Confinment of household members

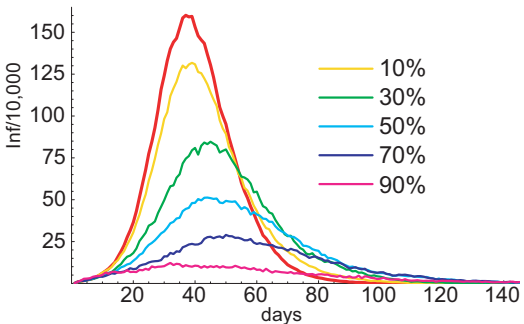

Figure 6

Impact of interventions on infection curves of simulated outbreaks.

Table 6: Reactive vaccination of $70 \%$ of the susceptible population according to the interval between implementation and identification of the first case in the community. Estimates are cumulative numbers per 100 inhabitants, unless otherwise specified.

\begin{tabular}{|c|c|c|c|c|}
\hline \multirow[t]{3}{*}{ Outcomes } & \multicolumn{4}{|c|}{ Interval (days) } \\
\hline & \multicolumn{2}{|c|}{$\begin{array}{c}0 \\
\text { (Outbreak, } n=121 \text { ) }\end{array}$} & \multicolumn{2}{|c|}{$\begin{array}{c}28 \\
\text { (Outbreak, } n=122)\end{array}$} \\
\hline & Mean & Minimum-Maximum & Mean & Minimum-Maximum \\
\hline \multicolumn{5}{|l|}{ Infections } \\
\hline Total & 4.2 & $0.5-15.7$ & 36.1 & $2.0-46.9$ \\
\hline Children $^{a}$ & 8.6 & $0.7-31.5$ & 62.6 & $4.6-77.7$ \\
\hline Adults $^{a}$ & 3.0 & $0.4-11.9$ & 29.7 & $1.4-40.2$ \\
\hline Elderly ${ }^{a}$ & 1.6 & $0.0-5.8$ & 18.1 & $0.5-27.8$ \\
\hline Physician visits ${ }^{b}$ & 1.6 & $0.0-10.3$ & 23.9 & $|.3-3| .2$ \\
\hline Hospital admissions & 0.15 & $0.01-0.5$ & 1.34 & $0.06-1.92$ \\
\hline Deaths & 0.033 & $0-0.14$ & 0.29 & $0.02-0.51$ \\
\hline Lost workdays $\underline{ }$ & 11 & $\mathrm{I}-44$ & 103 & $5-137$ \\
\hline Vaccination & 69.8 & 69-71 & 61.6 & $44-7 \mid$ \\
\hline
\end{tabular}

aPer 100 individuals of a given age

bPhysician visits for 'flu-like' illness (excludes visits for influenza vaccination)

sPer 100 working adults 
Table 7: Impact of closing institutions when $>5$ infections per 1000 subjects are observed in the community. Estimates are cumulative numbers per 100 inhabitants, unless otherwise specified.

\begin{tabular}{|c|c|c|c|c|}
\hline \multirow[t]{2}{*}{ Outcomes } & \multicolumn{2}{|c|}{$\begin{array}{c}\text { Closing schools } \\
\text { (Outbreak, } n=11 \mathrm{I})\end{array}$} & \multicolumn{2}{|c|}{$\begin{array}{l}\text { Closing schools and workplaces } \\
\text { (Outbreak, } n=101 \text { ) }\end{array}$} \\
\hline & Mean & Minimum-Maximum & Mean & Minimum-Maximum \\
\hline \multicolumn{5}{|l|}{ Infections } \\
\hline Total & 9.7 & $0.5-19.5$ & 1.1 & $0.6-2.1$ \\
\hline Children $^{a}$ & 10.3 & $1.6-23.1$ & 2.0 & $0.6-3.8$ \\
\hline Adults $^{a}$ & 9.9 & $0.6-23.7$ & 0.8 & $0.4-1.5$ \\
\hline Elderly ${ }^{a}$ & 6.1 & $0.3-14.5$ & 0.8 & $0.1-3.2$ \\
\hline Physician visits & 6.4 & $0.6-\mid 4.1$ & 0.7 & $0.4-1.4$ \\
\hline Hospital admissions & 0.36 & $0.03-0.9$ & 0.04 & $0.0-0.11$ \\
\hline Deaths & 0.081 & $0-0.3$ & 0.009 & $0.0-0.04$ \\
\hline Lost workdays ${ }^{b}$ & 324 & $80-464$ & 1885 & $977-5484$ \\
\hline Duration of closure (days) & 101 & $13-107$ & 27 & $14-78$ \\
\hline
\end{tabular}

aPer 100 individuals of a given age

bPer 100 working adults

demics, including the devastating 1917/1918 pandemic. This value was consistent with that reported in previous studies, where $R_{0}$ ranged from 1.4 to $2.4[7,8]$. It should be noted that a random choice of the initial infected individual would lead to a strong underestimation of $R_{0}(1.4 \mathrm{in}$ our model). Findings would also be most sensitive to parameters governing the natural history of influenza illness or health-care use. One-way sensitivity analysis showed that the lengths of the latent or incubation periods or the proportion of physician visits occurring during the first day of illness might strongly modify the dynamics of the epidemic or the effectiveness of interventions (see Additional files 1 and 2). Changes that occur during epidemics, such as increased virus fitness for human-tohuman transmission [41] and spontaneous changes in meeting rates in response to the perceived risk, must also be considered. The severity of an epidemic would also be highly sensitive to the efficacy of preventive or therapeutic treatments or vaccination, efficiency of case identification, timely implementation of control measures, population coverage, and public compliance [42]. The number of unknown parameters is too large for meaningful sensitivity analysis. In addition, the characteristics of the next pandemic influenza virus strain cannot be reliably predicted, and neither can the effectiveness of control measures. For example, a critical factor not included in this work is the possible emergence of resistance to antiviral drugs $[43,44]$. However, it could be useful to collect pandemic-independent information on patterns of social meetings and the precise mechanism by which influenza usually spreads during winter epidemics in temperate countries. The choice of the BA scale-free network for describing person-to-person meetings within places of occupation may be questionable [45], but BA networks generate broad heterogeneity in meeting patterns, which may contribute to generating 'superspreading' events [46].
The $20 / 80$ rule, which suggests that $20 \%$ of individuals are responsible for $80 \%$ of transmission events, can be tested on epidemiological datasets [47].

\section{Conclusion}

This flexible tool can help to determine the interventions most likely to contain an influenza pandemic. At present, our results support the stockpiling of antiviral drugs and accelerated development of vaccines.

\section{Abbreviations}

BA Barabasi-Albert

SD standard deviation

\section{Competing interests}

F Carrat has received fees for consultancies from Roche, GlaxoSmithKline, Chiron, and Aventis in the past five years. The other authors declare that they have no competing interests.

\section{Authors' contributions}

FC conceived and supervised the study and drafted the manuscript. JL, HL, and VS developed the simulation model and carried out the simulations. CL and HW conceived the study and helped draft the manuscript. All authors read and approved the final manuscript. 


\section{Additional material}

\section{Additional File 1}

PDF file One-way sensitivity analysis figures. A PDF file showing oneway sensitivity analyses of the reference scenario (Figure 7a) and a "combined interventions" scenario including the coverage of $70 \%$ of affected households, with treatment of the index patient, prophylaxis of household contacts, and confinement to home of all household members (Figure $7 b$ ), to parameters governing the natural history of influenza infection or healthcare use. The red curves describe simulated outbreaks with the parameter values used in the manuscript.

Click here for file

[http://www.biomedcentral.com/content/supplementary/1741-

7015-4-26-S1.pdf]

\section{Additional File 2}

Word file One-way sensitivity analysis table. A Word file showing oneway sensitivity analyses of the reference and the "combined interventions" scenarios to parameters governing the natural history of influenza infection or healthcare use.

Click here for file

[http://www.biomedcentral.com/content/supplementary/1741-

7015-4-26-S2.doc]

\section{Acknowledgements}

This work was partly supported by INSERM and by the European Union Framework $6^{\text {th }}$ programme - scientific support to policy, INFTRANS project.

\section{References}

I. Avian influenza: assessing the pandemic threat [http:// www.who.int/csr/disease/influenza/H5N I-9reduit.pdf]

2. Stohr K, Esveld M: Public health. Will vaccines be available for the next influenza pandemic? Science 2004, 306:2 195-2196.

3. Bresson JL, Perronne C, Launay O, Gerdil C, Saville M, Wood J Hoschler K, Zambon MC: Safety and immunogenicity of an inactivated split-virion influenza A/Vietnam/II94/2004 (H5NI) vaccine: phase I randomised trial. Lancet 2006 , 367:1657-1664.

4. Treanor JJ, Campbell JD, Zangwill KM, Rowe T, Wolff M: Safety and immunogenicity of an inactivated subvirion influenza $A$ (H5NI) vaccine. N Engl J Med 2006, 354: |343-I35I.

5. Ferguson NM, Cummings DA, Cauchemez S, Fraser C, Riley S, Meeyai A, lamsirithaworn S, Burke DS: Strategies for containing an emerging influenza pandemic in Southeast Asia. Nature 2005, 437:209-214.

6. Longini IM Jr, Nizam A, Xu S, Ungchusak K, Hanshaoworakul W, Cummings DA, Halloran ME: Containing pandemic influenza at the source. Science 2005, 309:1083-1087.

7. Ferguson NM, Cummings DA, Fraser C, Cajka JC, Cooley PC, Burke DS: Strategies for mitigating an influenza pandemic. Nature 2006, 442:448-452.

8. Germann TC, Kadau K, Longini IM Jr, Macken CA: Mitigation strategies for pandemic influenza in the United States. Proc Nat Acad Sci USA 2006, 103:5935-5940.

9. Longini IM Jr, Halloran ME, Nizam A, Yang Y: Containing pandemic influenza with antiviral agents. Am J Epidemiol 2004 159:623-633.

10. Treanor JJ, Hayden F: Volunteer challenge studies. In Textbook of Influenza Edited by: Nicholson KG, Webster RG, Hay AJ. London: Blackwell Science; 1998:517-537.

II. Carrat F, Vergu E, Ferguson NM, Cauchemez S, Leach S, Valleron AJ: Time lines of infection and disease in human influenza [abstract]. In 46th Interscience Conference on Antimicrobial Agents and Chemotherapy: 27-30 September 2006; abstract number V-I698 Volume
455. San Francisco. Washington: American Society of Microbiology; 2006.

12. Carrat F, Sahler C, Rogez S, Leruez-Ville M, Freymuth F, Le Gales C, Bungener M, Housset B, Nicolas M, Rouzioux C: Influenza burden of illness: estimates from a national prospective survey of household contacts in France. Arch Intern Med 2002, 162:1842-1848.

13. Cauchemez S, Carrat F, Viboud C, Valleron AJ, Boelle PY: A Bayesian MCMC approach to study transmission of influenza: application to household Iongitudinal data. Stat Med 2004, 23:3469-3487.

14. Viboud C, Boelle PY, Cauchemez S, Lavenu A, Valleron AJ, Flahault A, Carrat F: Risk factors of influenza transmission in households. BrJ Gen Pract 2004, 54:684-689.

15. Calfee DP, Peng AW, Cass LM, Lobo M, Hayden FG: Safety and efficacy of intravenous zanamivir in preventing experimental human influenza A virus infection. Antimicrob Agents Chemother 1999, 43:1616-1620.

16. Doyle WJ, Skoner DP, Alper CM, Allen G, Moody SA, Seroky JT, Hayden FG: Effect of rimantadine treatment on clinical manifestations and otologic complications in adults experimentally infected with influenza A (HINI) virus. J Infect Dis 1998, 177:1260-1265.

17. Fritz RS, Hayden FG, Calfee DP, Cass LM, Peng AW, Alvord WG, Strober W, Straus SE: Nasal cytokine and chemokine responses in experimental influenza A virus infection: results of a placebo-controlled trial of intravenous zanamivir treatment. J Infect Dis 1999, 180:586-593.

18. Hayden FG, Jennings L, Robson R, Schiff G, Jackson H, Rana B, McClelland $G$, Ipe $D$, Roberts $N$, Ward $P$ : Oral oseltamivir in human experimental influenza B infection. Antivir Ther 2000, 5:205-2I3.

19. Hayden FG, Treanor JJ, Fritz RS, Lobo M, Betts RF, Miller M, Kinnersley N, Mills RG, Ward P, Straus SE: Use of the oral neuraminidase inhibitor oseltamivir in experimental human influenza: randomized controlled trials for prevention and treatment. JAMA 1999, 282: I240-1246.

20. Hayden FG, Fritz R, Lobo MC, Alvord W, Strober W, Straus SE: Local and systemic cytokine responses during experimental human influenza A virus infection. Relation to symptom formation and host defense. I Clin Invest 1998, 10 1:643-649.

21. Walker JB, Hussey EK, Treanor JJ, Montalvo A Jr, Hayden FG: Effects of the neuraminidase inhibitor zanamavir on otologic manifestations of experimental human influenza. J Infect Dis 1997 , 176:1417-1422

22. Frost WH: Epidemiology of influenza. JAMA 1919, 73:3।3-3।8.

23. Glezen WP: Emerging infections: pandemic influenza. Epidemiol Rev 1996, 18:64-76.

24. Agence technique de l'information sur I'hospitalisation [http://www.atih.sante.fr/]

25. La situation démographique en France [http://www.ined.fr/fr/ pop chiffres/france/]

26. Barabasi AL, Albert R: Emergence of scaling in random networks. Science 1999, 286:509-5I2.

27. Newman M: The structure and function of complex networks. SIAM REVIEW 2003, 45: 167-256.

28. Barabasi A, Albert $\mathrm{R}$, Jeong $\mathrm{H}$ : Mean-field theory for scale-free random networks. Physica A 1999, 272:173-187.

29. Watts DJ, Strogatz $\mathrm{SH}$ : Collective dynamics of 'small-world' networks. Nature 1998, 393:440-442.

30. Andersson $\mathrm{H}$ : Limit theorems for a random graph epidemic model. Ann Appl Prob 1998, 8: 1331-1349.

3I. Jordan WS Jr, Denny FW Jr, Badger GF, Curtiss C, Dingle JH, Oseasohn R, Stevens DA: A study of illness in a group of Cleveland families. XVII. The occurrence of Asian influenza. Am J Hyg 1958, 68:190-212.

32. Mills CE, Robins JM, Lipsitch M: Transmissibility of 1918 pandemic influenza. Nature 2004, 432:904-906.

33. Simonsen L, Clarke MJ, Schonberger LB, Arden NH, Cox NJ, Fukuda $\mathrm{K}$ : Pandemic versus epidemic influenza mortality: a pattern of changing age distribution. J Infect Dis 1998, 178:53-60.

34. Moscona $A$ : Neuraminidase inhibitors for influenza. $N$ Engl J Med 2005, 353:1363-1373.

35. Cooper NJ, Sutton AJ, Abrams KR, Wailoo A, Turner D, Nicholson KG: Effectiveness of neuraminidase inhibitors in treatment and prevention of influenza $A$ and $B$ : systematic review and 
meta-analyses of randomised controlled trials. BMJ 2003, 326: 1235 .

36. Hayden FG, Belshe R, Villanueva C, Lanno R, Hughes C, Small I, Dutkowski R, Ward P, Carr J: Management of influenza in households: a prospective, randomized comparison of oseltamivir treatment with or without postexposure prophylaxis. J Infect Dis 2004, 189:440-449.

37. Smith PG, Rodrigues LC, Fine PE: Assessment of the protective efficacy of vaccines against common diseases using case-control and cohort studies. Int J Epidemiol 1984, 13:87-93.

38. Nichol KL, Lind A, Margolis KL, Murdoch M, McFadden R, Hauge M, Magnan S, Drake M: The effectiveness of vaccination against influenza in healthy, working adults. N Engl J Med 1995, 333:889-893.

39. Lloyd-Smith JO, Schreiber SJ, Kopp PE, Getz WM: Superspreading and the effect of individual variation on disease emergence. Nature 2005, 438:355-359.

40. Newman ME: Properties of highly clustered networks. Phys Rev E Stat Nonlin Soft Matter Phys 2003, 68:026121.

4I. Antia R, Regoes RR, Koella JC, Bergstrom CT: The role of evolution in the emergence of infectious diseases. Nature 2003, 426:658-66I.

42. Drake JM: Limits to forecasting precision for outbreaks of directly transmitted diseases. PLoS Med 2006, 3:e3.

43. Kiso M, Mitamura K, Sakai-Tagawa Y, Shiraishi K, Kawakami C, Kimura K, Hayden FG, Sugaya N, Kawaoka Y: Resistant influenza A viruses in children treated with oseltamivir: descriptive study. Lancet 2004, 364:759-765.

44. Le QM, Kiso M, Someya K, Sakai YT, Nguyen TH, Nguyen KH, Pham ND, Ngyen HH, Yamada S, Muramoto Y, Horimoto T, Takada A, Goto $\mathrm{H}$, Suzuki T, Suzuki Y, Kawaoka Y: Avian flu: isolation of drug-resistant H5NI virus. Nature 2005, 437: I 108.

45. Eubank S, Guclu H, Kumar VS, Marathe MV, Srinivasan A, Toroczkai $\mathrm{Z}$, Wang $\mathrm{N}$ : Modelling disease outbreaks in realistic urban social networks. Nature 2004, 429: $180-184$.

46. Galvani AP, May RM: Epidemiology: dimensions of superspreading. Nature 2005, 438:293-295.

47. Woolhouse ME, Dye C, Etard JF, Smith T, Charlwood JD, Garnett GP, Hagan P, Hii JL, Ndhlovu PD, Quinnell RJ, Watts CH, Chandiwana SK, Anderson RM: Heterogeneities in the transmission of infectious agents: implications for the design of control programs. Proc Natl Acad Sci USA 1997, 94:338-342.

48. Frank AL, Taber LH, Wells JM: Comparison of infection rates and severity of illness for influenza $A$ subtypes HINI and H3N2. I Infect Dis 1985, 15 I:73-80.

49. Axtell RL: Zipf distribution of U.S. firm sizes. Science 200I, 293: $1818-1820$.

\section{Pre-publication history}

The pre-publication history for this paper can be accessed here:

http://www.biomedcentral.com/1741-7015/4/26/prepub
Publish with Biomed Central and every scientist can read your work free of charge

"BioMed Central will be the most significant development for disseminating the results of biomedical research in our lifetime."

Sir Paul Nurse, Cancer Research UK

Your research papers will be:

- available free of charge to the entire biomedical community

- peer reviewed and published immediately upon acceptance

- cited in PubMed and archived on PubMed Central

- yours - you keep the copyright

Submit your manuscript here:

http://www.biomedcentral.com/info/publishing_adv.asp
BiolMedcentral 